\title{
The Effect of Humic Acid on the Formation and Solubility of Secondary Solid Phases of Polyvalent Metal lons
}

\author{
Stella Antoniou ${ }^{\#}$ and loannis Pashalidis*
}

\author{
Department of Chemistry, University of Cyprus, P.O. Box 20537, 1678 Nicosia, Cyprus
}

\begin{abstract}
The paper presents and discusses experimental data regarding the effect of natural organic matter (e.g. humic acid) on the formation and solubility of secondary solid phases of polyvalent metal ions (e.g. $M(V I), M(I V)$, $M(I I I)$ ) in aqueous solutions of $0.1 \mathrm{M} \mathrm{NaClO}_{4}$ and under normal atmospheric conditions. The experimental work has been carried out using hexavalent uranium as analogue for $\mathrm{M}(\mathrm{VI})$, tetravalent thorium, cerium and zirconium as analogues for $\mathrm{M}(\mathrm{IV})$ and trivalent samarium and neodymium as analogues for $\mathrm{M}(\mathrm{III})$. The solid phases under investigation have been prepared by alkaline precipitation in the presence and absence of humic acid and characterized by TGA, ATR-FTIR, XRD and solubility measurements. The experimental data obtained indicate generally that the solid phases, which are formed in the absence of humic acid, are stable and remain the solubility limiting solid phases even in the presence of increased humic acid concentration (up to $0.5 \mathrm{~g} \mathrm{I}^{-1}$ ) in solution. Although polyvalent metal ions form very stable complex with humic acid, upon base addition in the $M(z)$-humic acid system decomplexation of the previously formed $M(z)$ humate complexes and precipitation of two distinct phases occurs, namely, the inorganic and the organic phase. The latter is adsorbed on the particle surface of the former. However, natural organic matter (humic acid) affects the particle size of the solid phases and may lead to reduction of redox-sensitive species. Generally, increasing humic acid concentration results in decreasing crystallite size of the inorganic solid phase. The extent of the effect depends inversely on the solid phase stability.
\end{abstract}

Keywords: Polyvalent metal ions, humic acid, solid phase formation, solubility.

\section{INTRODUCTION}

The long-term performance assessment for the safe disposal of (radio)toxic elements (e.g. heavy metal ions) in underground geological formations (e.g. clay formations, granite, etc.) requires mechanistic knowledge of the chemical behaviour of the metal ions in aquatic systems, because usually only through underground aquifers migration and dispersion of the (radio)toxic elements in the environment is possible [1]. There is particular interest regarding actinides (e.g. U, $\mathrm{Pu}, \mathrm{Np}, \mathrm{Am} \mathrm{Cm}$ ), because of the amounts produced in fission reactors and their long-lived radionuclides, which are generally highly radiotoxic alpha-radiation emitters.

Actinides maybe present in aqueous solution in different oxidation states and there are examples like plutonium, which can exist in aqueous solutions simultaneously in four different thermodynamically stable oxidations states (e.g. $\mathrm{Pu}(\mathrm{III}), \mathrm{Pu}(\mathrm{IV}), \mathrm{Pu}(\mathrm{V})$ and $\mathrm{Pu}(\mathrm{VI}))$. Actinides and lanthanides show usually similar chemical behaviour in solid and aqueous phase, if present in the same oxidation state [2]. Because of the direct similarities between the solid and aqueous phase chemistry of some of the actinides and lanthanides and the fact, that lanthanides are non-radioactive and possess excellent fluorescent properties, we have used

\footnotetext{
*Address corresponding to this author at the Department of Chemistry, University of Cyprus, P.O. Box 20537, 1678 Nicosia, Cyprus; Tel: +357 22892785; Fax: +357 22892801; E-mail: pspasch@ucy.ac.cy

\#Co-Author E-mail: stella_antoniou_1@hotmail.com
}

$\mathrm{Ln}$ (III) ions as non-radioactive analogues for the $\mathrm{An}$ (III) in this study [3].

The chemical behaviour of polyvalent metal ions in natural systems is governed by hydrolysis, complexation with naturally occuring ligands, colloid generation, interaction with mineral surfaces and solid phase formation [1]. The investigation of formed solid phases is of particular interest because secondary phases may represent important sinks for (radio)toxic metal ions within nuclear spent fuel and (radio)toxic waste repositories and determine their solubility and mobility in the geosphere. Therefore, understanding of the fate and transport mechanisms of those elements in natural and contaminated sites requires the investigation of the solubility and relative stability of the solid phases formed under natural conditions [1]. There are several studies regarding solid phase formation and stability [4-7] and specific studies on the impact of naturally occurring matter (NOM) on the formation of secondary phases [8-13] to understand better the effect of NOM on the solid phase stability and solubility. Investigations on the impact of NOM on solid phase formation and stability are of fundamental importance because NOM (here represented by humic acid) is omnipresent in natural waters and may affect the solution chemistry of metal ions (e.g. complex and colloid formation). In vivo and in vitro studies clearly show, that organic matter strongly affects crystal growth as well as texture of minerals and inorganic solids [8-15]. 
In this paper we present and discuss experimental data from studies regarding the effect of natural organic matter (NOM) and particularly humic acid on the solid phase formation of polyvalent metal ions in aqueous solutions. The solid phases, which have been studied are: $\mathrm{Nd}(\mathrm{OH}) \mathrm{CO}_{3}, \mathrm{Nd}_{2}\left(\mathrm{CO}_{3}\right)_{3}, \quad \mathrm{NdPO}_{4}, \mathrm{Sm}(\mathrm{OH}) \mathrm{CO}_{3}$, $\mathrm{Sm}_{2}\left(\mathrm{CO}_{3}\right)_{3}, \quad \mathrm{SmPO}_{4}, \quad \mathrm{Th}(\mathrm{OH})_{4}, \quad \mathrm{Zr}(\mathrm{OH})_{4}, \quad \mathrm{Ce}(\mathrm{OH})_{4}$, $\mathrm{UO}_{2}(\mathrm{OH})_{2}$ and $\mathrm{UO}_{2} \mathrm{CO}_{3}$.

\section{MATERIALS AND METHODS}

\subsection{Solid Phase Preparation and Characterisation}

$\mathrm{M}(\mathrm{z})$ stock solutions were prepared by dissolution of $\mathrm{M}\left(\mathrm{NO}_{3}\right) \mathrm{z}$ salts (Aldrich $\mathrm{Co}$ ) in aqueous $0.1 \mathrm{M} \mathrm{NaClO}_{4}$. Solid phases were prepared by alkaline precipitation of a $50 \mathrm{~mL} \mathrm{M(z)} \mathrm{solution.} \mathrm{HA} \mathrm{solutions} \mathrm{used} \mathrm{in} \mathrm{this} \mathrm{study}$ were prepared from Aldrich humic acid, purified and characterized as described elsewhere [16].

The precipitates have been characterized by thermogravimetric analysis (TGA-50 Shimadzu), and Xray diffraction (XRD 6000 Shimadzu). The evaluation of the particle/crystallite sizes was performed using the Scherrer equation (1).

$t=k \cdot \lambda /(B \cdot \cos \theta)$

In equation $1, t$ is the averaged dimension of crystallites, $\mathrm{k}$ is the Scherrer constant (assumed to be $0.98), \lambda$ is the wavelength derived from the XRD measurements; $B$ is the FWHM of the most intense reflection; and $\theta$ the angle of incidence/reflectance (in radians) [21]. In addition FTIR-ATR spectroscopic measurements have been performed on dried solid samples after separation by centrifugation as described elsewhere [8-13].

\subsection{Solubility Measurements}

The solubility studies were carried out with solid phases (about $100 \mathrm{mg}$ ), prepared in the presence and absence of $\mathrm{HA}$, in conduct with $50 \mathrm{~mL}$ of $0.1 \mathrm{M} \mathrm{HClO}_{4}$ solutions. The $\mathrm{pH}$ was adjusted by addition of $0.1 \mathrm{M}$ $\mathrm{NaOH}$ or $0.1 \mathrm{M} \mathrm{HClO}_{4}$. Following equilibration time (from 2 weeks to one year), $\mathrm{pH}$ was measured using a glass electrode and the analytical $\mathrm{M}(\mathrm{z})$ concentration in solution was determined spectrophotometrically (UV 2401 PC Shimadzu) by means of arsenazo III according to a previously described method [17]. Prior concentration determination the test solution was ultrafiltrated using $0.45 \mathrm{~mm}$ membrane filters to remove any solid phase particulates from the solution.

\section{RESULTS AND DISCUSSION}

\subsection{Trivalent Metal lons}

The trivalent lanthanides $\mathrm{Nd}(\mathrm{III})$ and $\mathrm{Sm}$ (III) have been used as analoques for trivalent metal-ions and particularly trivalent actinides. The solid phases which have been studied are $\mathrm{Ln}(\mathrm{OH}) \mathrm{CO}_{3}, \mathrm{Ln}_{2}\left(\mathrm{CO}_{3}\right)_{2}$ and $\mathrm{LnPO}_{4}$. $\mathrm{Ln}(\mathrm{OH}) \mathrm{CO}_{3}$ and $\mathrm{LnPO}_{4}$ are formed and are stable under normal atmospheric conditions, whereas $\mathrm{Ln}_{2}\left(\mathrm{CO}_{3}\right)_{2}$ has been precipitated under $100 \% \mathrm{CO}_{2}$ atmosphere. According to the spectroscopic studies there is clear indication that precipitation (even in the presence of increased humic acid concentration results in the formation of the pure solids $[12,13]$. A representative FTIR-ATR of $\mathrm{Nd}_{2}\left(\mathrm{CO}_{3}\right)_{2}$ solid formed in humic acid-free solution and in the presence of humic acid $\left([\mathrm{HA}]=0.5 \mathrm{~g} \mathrm{I}^{-1}\right)$ is given in Figure 1. Formation of solids containing in their structure humic acid isn't observed and the humic acid co-precipitated with the inorganic solid is just physically adsorbed on the surface of the solid phase particles. The separation into an inorganic and an organic phase during precipitation is somehow unexpected, taking into account the relatively high affinity of humic acid for the $\operatorname{Ln}(\mathrm{III})$ ions resulting in stable Ln(III)-humate complexes in solution

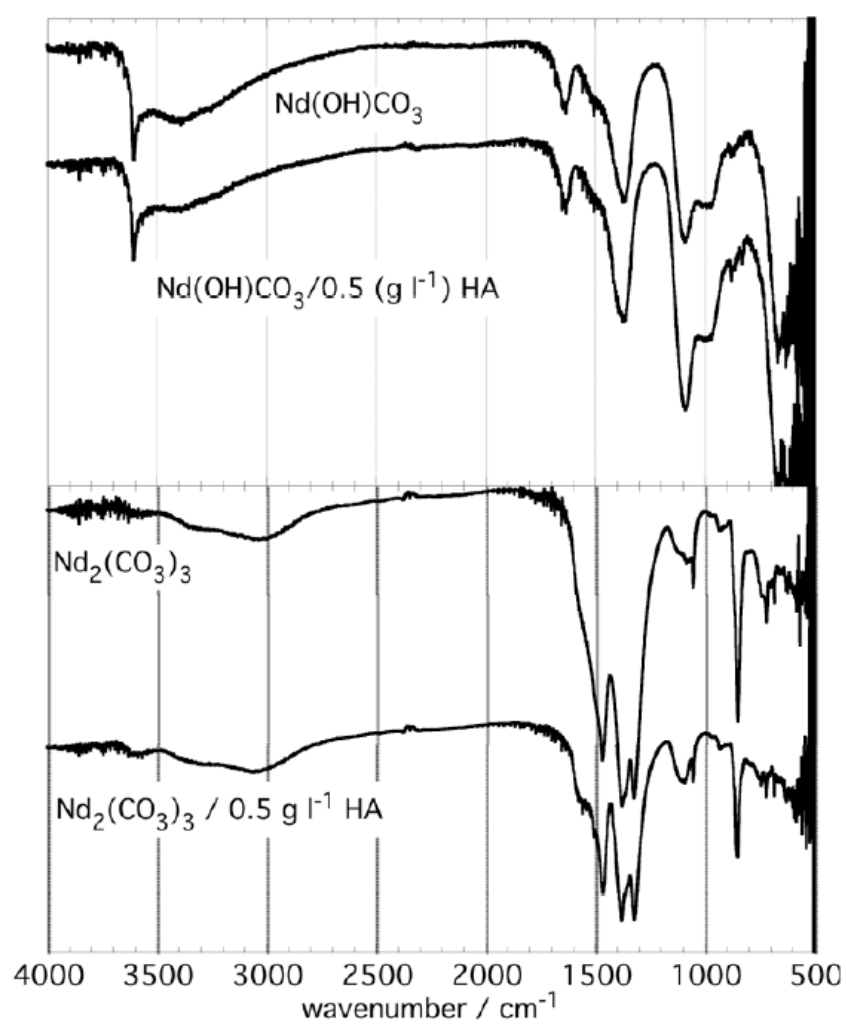

Figure 1: ATR-FTIR spectrum of $\mathrm{NdOHCO}_{3}$ and $\mathrm{Nd}_{2}\left(\mathrm{CO}_{3}\right)_{2}$ formed in $\mathrm{HA}$-free solution and in the presence of $\mathrm{HA}([\mathrm{HA}]=$ $\left.0.5 \mathrm{gl}^{-1}\right)$. 


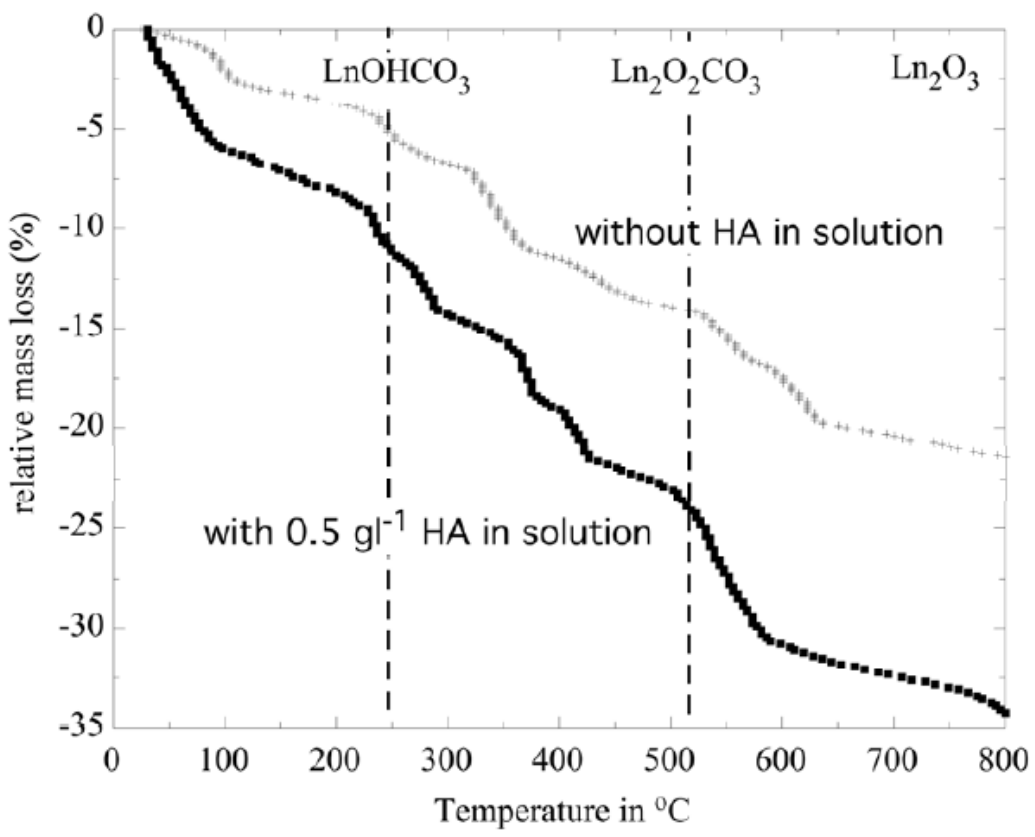

Figure 2: TGA curves of $\mathrm{NdOHCO}_{3}$ formed in $\mathrm{HA}$-free solution and in the presence of $\mathrm{HA}\left([\mathrm{HA}]=0.5 \mathrm{~g} \mathrm{l}^{-1}\right.$ ).

[18]. The formation constants of the Ln(III)-humate complexes ( $\log B \sim 7$ ) are relatively larger than the corresponding formation constants for hydrolysis and carbonate complexation $\left(\log \beta_{1} \sim 6\right.$ and $\log \beta_{1} \sim 5$, respectively) [1]. However, in the alkaline $\mathrm{pH}$ range $(\mathrm{pH} 10)$, where the solid phase formation occurs, the concentration of the hydroxide and carbonate ligands becomes predominant resulting in the decomplexation of the $\mathrm{Ln}(\mathrm{III})$-humate complex and the formation of the $\mathrm{Ln}(\mathrm{OH}) \mathrm{CO}_{3}$ and $\mathrm{Ln}_{2}\left(\mathrm{CO}_{3}\right)_{2}$ solids $[12,13]$.

Thermogravimetric analysis (TGA) data of the $\mathrm{Ln}(\mathrm{III})$ solids (e.g. $\mathrm{Ln}(\mathrm{OH}) \mathrm{CO}_{3}$ and $\mathrm{Ln}_{2}\left(\mathrm{CO}_{3}\right)_{2}$ ) prepared in the presence and absence of humic acid (Figure 2) show that the TGA curves remain similar but the mass losses for physically and chemically bound water increase significantly $(\sim 15 \%)$ for humic acid containing solids compared to the corresponding pure samples [12]. The higher mass loss corresponds to water and humic acid, which are adsorbed onto solid phase particles. Adsorption of humic acid on solid phase particles increases the water-holding capacity of the material, because humic acid, which is adsorbed onto the solid particles, affects their texture and water-holding capacity [19].

In order to investigate possible effects of the adsorbed humic acid on the solid phase texture (e.g. particle size) XRD measurements have been performed. The XRD measurements (Figure 3) show, that humic acid doesn't have any impact on the solid phase composition but affects the crystallite size of the
$\mathrm{Nd}(\mathrm{III})$ and the Sm(III) solid phases [12, 13]. The corresponding data, which are summarized in Table 1 show that the crystallite size of the $\mathrm{Nd}(\mathrm{III})$ solids decreases, whereas the crystallite size of Sm(III) solids increases with increasing humic acid concentration in solution. The opposite effect of humic acid on the particle size of the two different lanthanide solid phases can be attributed to the different ionic radii of the corresponding elements [2, 3]. Changes in particle size may affect accordingly the solid phase solubility because of microsolubility effects [20].

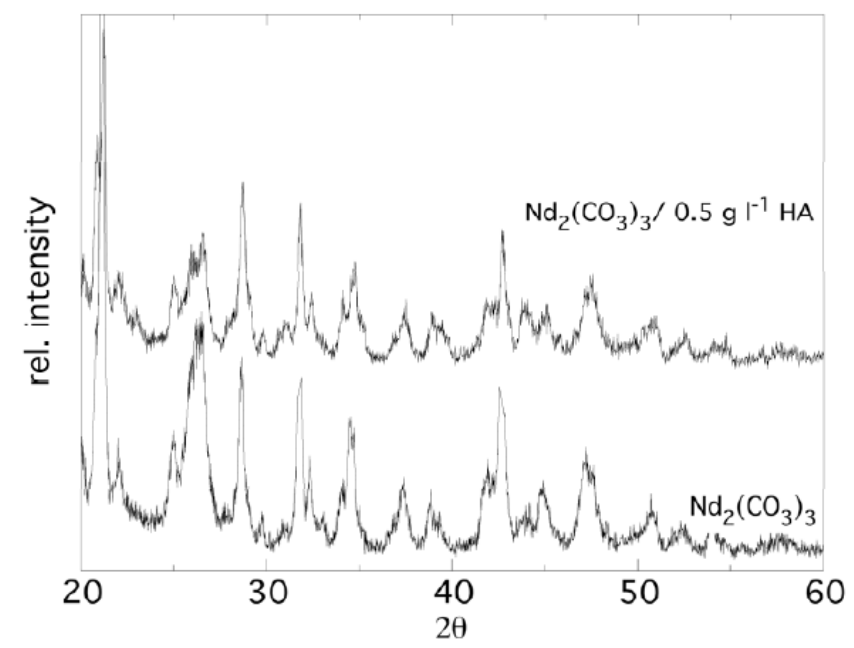

Figure 3: XRD diffractograms of $\mathrm{Nd}_{2}\left(\mathrm{CO}_{3}\right)_{3}$ solid phases prepared in $\mathrm{HA}$-free solution and in the presence of $\mathrm{HA}$ $\left([\mathrm{HA}]=0.5 \mathrm{~g} \mathrm{l}^{-1}\right)$.

In order to investigate possible microsolubility effects solubility experiments have been performed 
Table 1: Particle Size of the $\mathrm{Ln}_{2}\left(\mathrm{CO}_{3}\right)_{3}$ and $\mathrm{Ln}_{2}(\mathrm{OH}) \mathrm{CO}_{3}$ Solid Phases Precipitated in Aqueous Solutions of $0.1 \mathrm{M}$ $\mathrm{NaClO}_{4}$ Containing Various Amounts of Humic Acid. The Particle Size has been Estimated from the XRD Spectra/Peaks According to Scherrer Equation [21]

\begin{tabular}{|c|c|c|c|c|}
\hline [HA] in $\mathrm{mg} \mathrm{I}^{-1}$ & $\mathrm{Nd}_{2}\left(\mathrm{CO}_{3}\right)_{3}$ & $\mathrm{Sm}_{2}\left(\mathrm{CO}_{3}\right)_{3}$ & $\mathrm{Nd}(\mathrm{OH}) \mathrm{CO}_{3}$ & $\mathrm{Sm}(\mathrm{OH}) \mathrm{CO}_{3}$ \\
\hline & \multicolumn{4}{|c|}{ particle size in $\mathbf{~ m m ~}$} \\
\hline \hline 0.0 & 36.8 & 21.8 & 10.3 & 14.5 \\
\hline 0.1 & 17.9 & 24.2 & 9.4 & 15.8 \\
\hline 0.3 & 14.4 & 27.5 & 8.5 & 16.0 \\
\hline 0.5 & 14.2 & 54.5 & 8.1 & 16.5 \\
\hline
\end{tabular}

Table 2: Particle Size and the Corresponding Solubility Product of $\mathrm{UO}_{2}(\mathrm{OH})_{2}$ and $\mathrm{UO}_{2} \mathrm{CO}_{3}$ Solid Phases Prior and after Contact with Aqueous Solutions of $0.1 \mathrm{M} \mathrm{NaClO}_{4}$ Containing Various Amounts of Humic Acid. The Particle Size has been Estimated from the XRD Spectra/Peaks According to Scherrer Equation [21]

\begin{tabular}{|c|c|c|}
\hline$[\mathrm{HA}]$ in $\mathrm{mg} \mathrm{l}^{-1}$ & particle size in $\mathrm{nm}$ & $\log K_{s p}$ \\
\hline \multicolumn{3}{|c|}{$\mathrm{UO}_{2}(\mathrm{OH})_{2}$} \\
\hline 0 & 22.0 & -22.0 \\
\hline 0.1 & 18.0 & -22.0 \\
\hline 0.3 & 12.0 & -21.7 \\
\hline \multicolumn{3}{|c|}{$\mathrm{UO}_{2} \mathrm{CO}_{3}$} \\
\hline 0 & 40.0 & 13.7 \\
\hline 0.1 & 10.0 & 13.2 \\
\hline 0.3 & 10.0 & 13.2 \\
\hline
\end{tabular}

using $\mathrm{Ln}(\mathrm{OH}) \mathrm{CO}_{3}$ and $\mathrm{Ln}_{2}\left(\mathrm{CO}_{3}\right)_{2}$ solids, prepared in absence and presence of humic acid. The corresponding solubility data, which are shown in Figure 4, indicate that microsolubility effects (even small) are apparent, resulting (as expected) in lower solubility for $\mathrm{Sm}(\mathrm{III}) /$ humic acid- and slightly higher solubility for $\mathrm{Nd}(\mathrm{III}) /$ humic acid-solids, in comparison to the corresponding pure solids. However, these changes in the solubility are within the uncertainty found in literature regarding the values for the solubility products of the solids [6, 7]. On the other hand, no microsolubility effects have been observed in the case of the $\mathrm{MPO}_{4}$ solids and this is basically attributed to the stability of the corresponding solid phases.

\subsection{Tetravalent Metal lons}

According to Figure 5 ATR-FTIR spectroscopic measurements indicate that the spectra of $M(I V)$ solid phases prepared in the presence and absence of

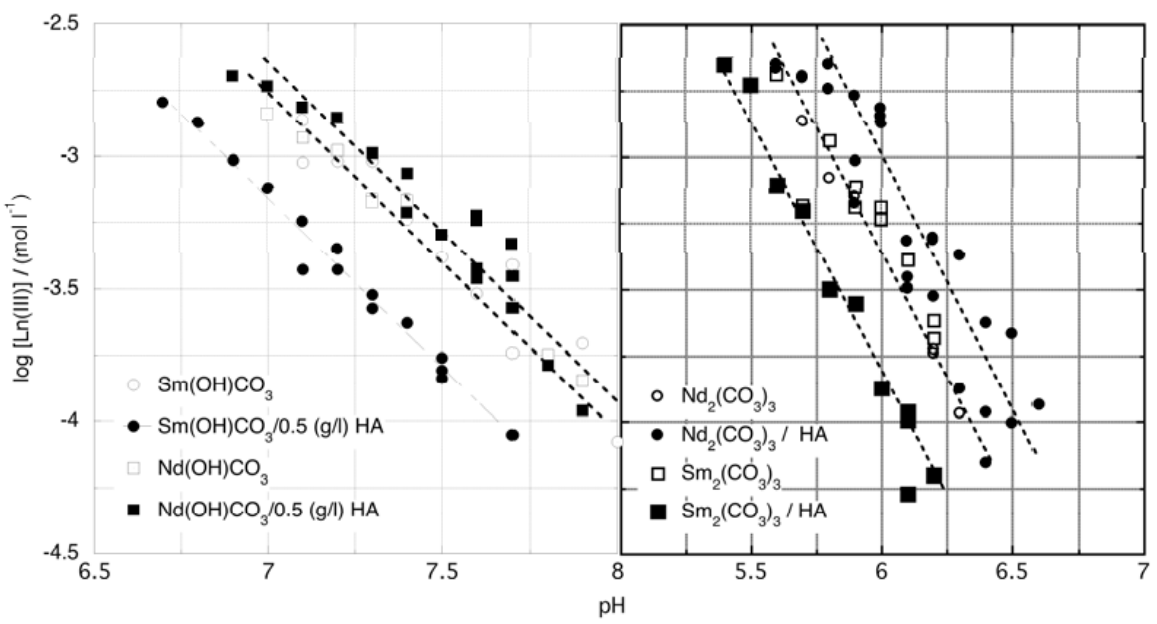

Figure 4: Solubility curves of the $\mathrm{LnOHCO}_{3}$ and $\mathrm{Ln}_{2}\left(\mathrm{CO}_{3}\right)_{2}$ solid phases prepared in presence and absence of $\mathrm{HA}$ ([HA]= $0.5 \mathrm{~g} \mathrm{l}^{-1}$ ) under normal atmospheric conditions and $100 \% \mathrm{CO}_{2}$-atmosphere, respectively. 
humic acid show similar features. The absence of characteristic peaks attributed to humic acid indicates that the amount of the organic matter adsorbed onto the solid phase particles is relatively low. On the other hand, analysis of the TGA curves of $\mathrm{M}(\mathrm{OH})_{4}$ solids before contact with humic acid solutions, results in mass losses (about 32\%), which according to stoichiometric calculation data correspond to the decomposition of $\mathrm{M}(\mathrm{OH})_{4}$ solid phases. After equilibration with humic acid solutions, the TGA curves remain almost the same but indicate a higher mass loss (about $5 \%$ ), which is attributed to excess physisorbed water on the humic acid treated solids (Figure 6). The increased water holding capacity of $\mathrm{M}(\mathrm{OH})_{4}$ contacted with humic acid solutions can be ascribed to the alteration of the solid by the humic acid macromolecules, which diffuse onto the solid phase affecting its texture and water-holding capacity [10,11].

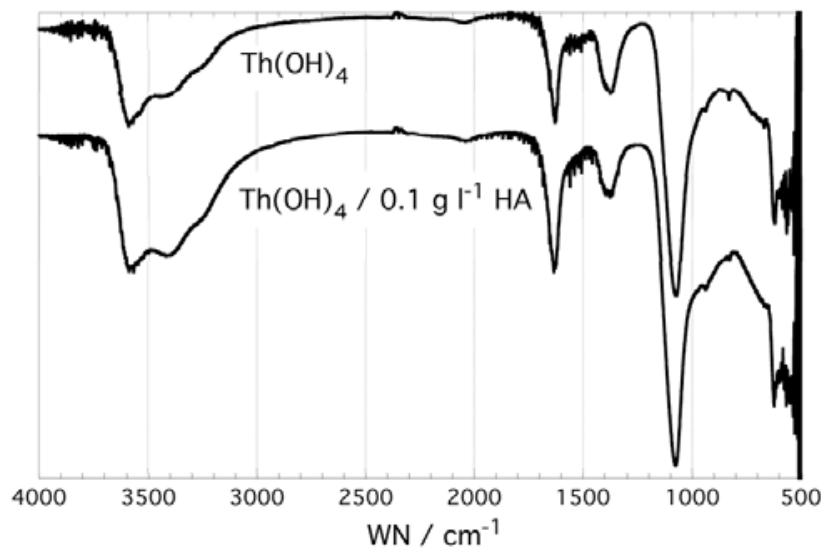

Figure 5: ATR-FTIR spectrum of $\mathrm{Th}(\mathrm{OH})_{4}$ precipitaed in HAfree solution and in the presence of $\mathrm{HA}\left([\mathrm{HA}]=0.5 \mathrm{~g} \mathrm{I}^{-1}\right)$ from aqueous solutions.

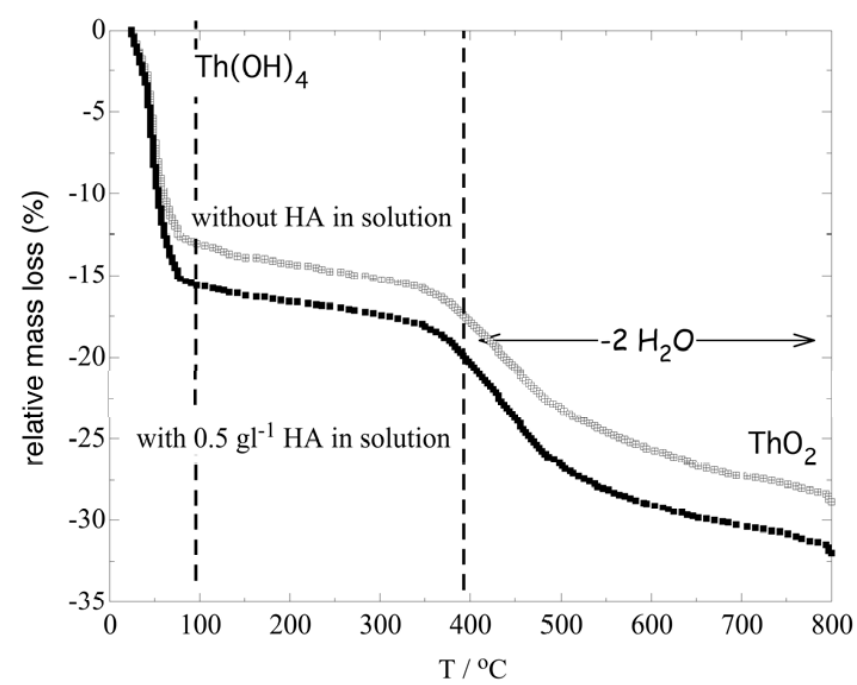

Figure 6: TGA curves of $\mathrm{Th}(\mathrm{OH})_{4}$ formed in HA-free solution and in the presence of $\mathrm{HA}\left([\mathrm{HA}]=0.5 \mathrm{~g} \mathrm{I}^{-1}\right)$.
In agreement with the FTIR spectra and the TGA data, the XRD measurements indicate only the presence of $\mathrm{M}(\mathrm{OH})_{4}$. According to XRD data, the presence of humic acid in solution does not affect the particle size of the $\mathrm{M}(\mathrm{OH})_{4}$ solid phases [10]. The absence of any effect on the crystallite size of $\mathrm{M}(\mathrm{OH})_{4}$ can be (similarly to $\mathrm{MPO}_{4}$ solid phases) attributed to their increased stability [2]. However, in the case of redox -sensitive metal ions such as Ce(IV) precipitation in the presence of humic acid results in partial reduction and formation of $\mathrm{Ce}$ (III) solid phases. Figure 7 shows the relative amount of $\mathrm{Ce}$ (IV) reduced to $\mathrm{Ce}(\mathrm{III})$ as a function of the humic acid concentration in solution during $\mathrm{Ce}(\mathrm{IV})$ precipitation.

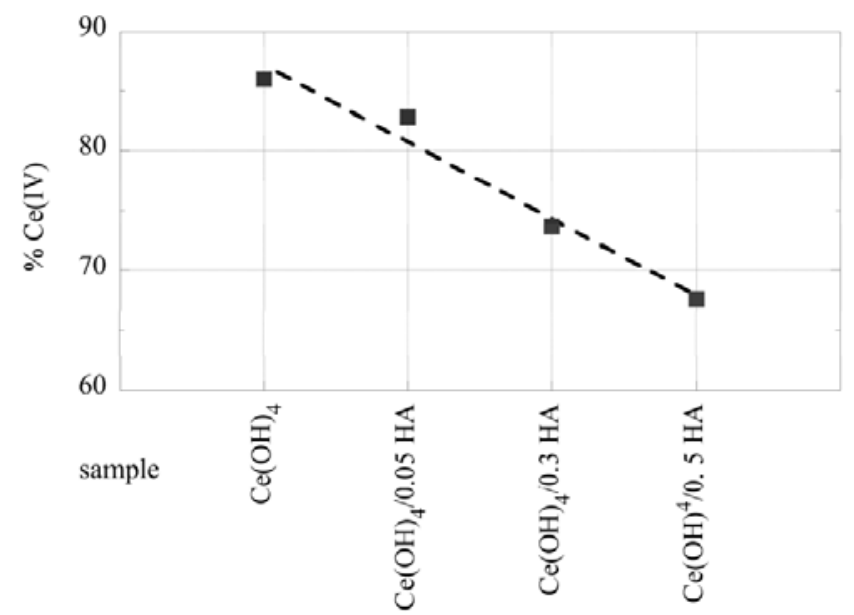

Figure 7: Relative amount of $\mathrm{Ce}(\mathrm{IV})$ reduced to $\mathrm{Ce}(\mathrm{III})$ as a function of the HA amount (in $\mathrm{mg} \mathrm{l}^{-1}$ ) in the aqueous solution.

The solubility measurements performed with $\mathrm{M}(\mathrm{OH})_{4}$ solids under normal atmospheric conditions in aquatic solutions of $0.1 \mathrm{M} \mathrm{NaClO}_{4}$ with and without humic acid have proven the formation of only $\mathrm{M}(\mathrm{OH})_{4}$ solid phases. Fluctuations observed in the $M(I V)$ concentration are attributed to the formation of $M(I V)$ colloids in the $\mathrm{pH}$ range 3-5. The formation of $\mathrm{Th}(\mathrm{IV})$ colloids has been confirmed by ultrafiltration experiments using membrane filters of different pore size $(0.45 \mu \mathrm{m}, \quad 0.22 \mu \mathrm{m}, \quad 30 \mathrm{kD}, 100 \mathrm{kD})$. The corresponding data show that the total M(IV) concentration in solution decreases significantly with decreasing the pore size of the filters used. Furthermore, lower M(IV) concentration in humic acidcontaining solution after ultrafiltration may indicate the formation of larger particles generated upon humic acid and $\mathrm{M}(\mathrm{IV})$-colloid interaction [10, 11].

\subsection{Hexavalent Metal lons}

Figure 8 shows ATR-FTIR spectra of $\mathrm{UO}_{2}(\mathrm{OH})_{2}$ and $\mathrm{UO}_{2} \mathrm{CO}_{3}$ solid phases precipitated in humic acid-free 


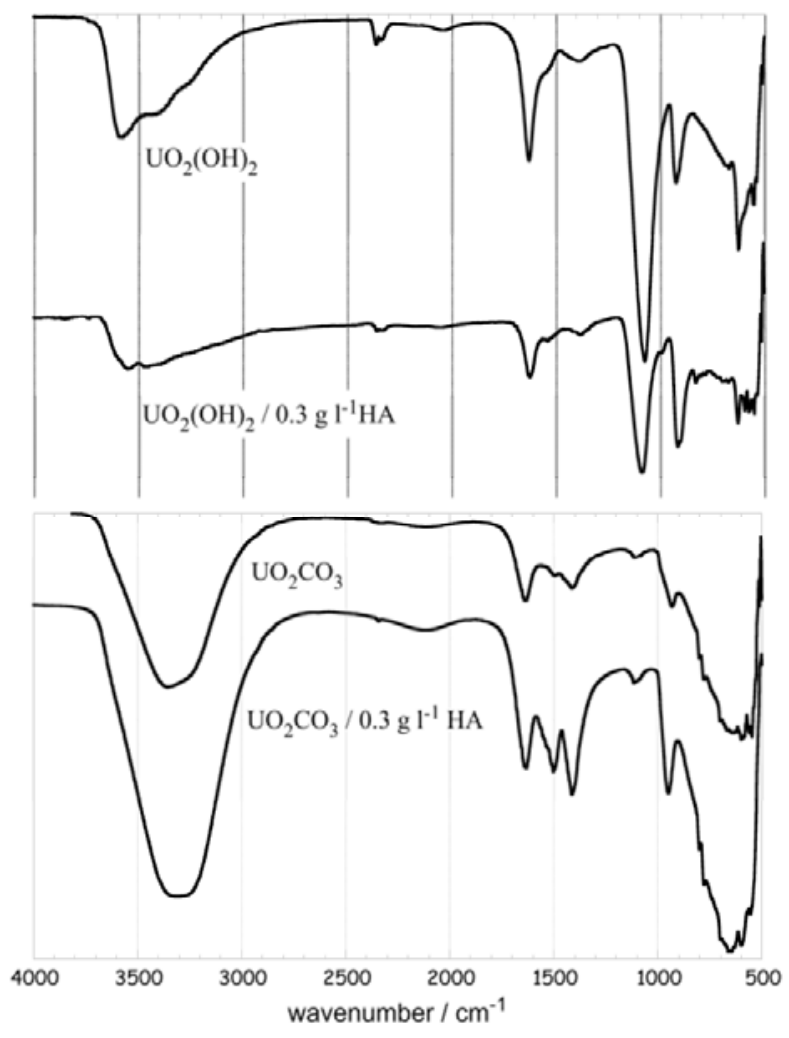

Figure 8: ATR-FTIR spectrum of $\mathrm{UO}_{2}(\mathrm{OH})_{2}$ and $\mathrm{UO}_{2} \mathrm{CO}_{3}$ formed in $\mathrm{HA}$-free solution and in the presence of $\mathrm{HA}([\mathrm{HA}]=$ $0.3 \mathrm{~g} \mathrm{l}^{-1}$ ).

and humic acid containing aqueous solutions and indicate the formation of only pure solids. $\mathrm{UO}_{2}(\mathrm{OH})_{2}$ is formed and is stable under normal atmospheric conditions, whereas $\mathrm{UO}_{2} \mathrm{CO}_{3}$ has been precipitated under $100 \% \quad \mathrm{CO}_{2}$-atmosphere. The TGA measurements (Figure 9) of the corresponding $\mathrm{U}(\mathrm{VI})$ solid phases (e.g. $\mathrm{UO}_{2}(\mathrm{OH})_{2}$ and $\mathrm{UO}_{2} \mathrm{CO}_{3}$ ) confirm their formation but show significantly higher water holding

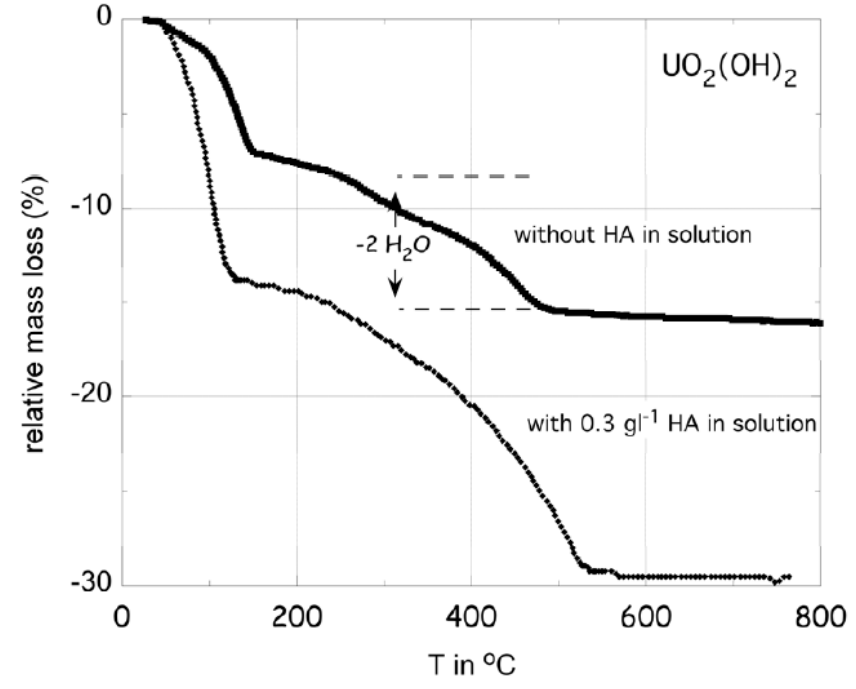

Figure 9: TGA curves of $\mathrm{UO}_{2}(\mathrm{OH})_{2}$ formed in $\mathrm{HA}$-free solution and in the presence of $\mathrm{HA}\left([\mathrm{HA}]=0.3 \mathrm{~g} \mathrm{I}^{-1}\right)$.

capacity ( 15\%), in the case of $U(\mathrm{VI})$ solid phases prepared in the presence of humic acid $[8,9]$.

The XRD data are in agreement with the data obtained from the TGA and FTIR measurements and indicate clearly the presence of only pure $\mathrm{U}(\mathrm{VI})$ solid phases (Figure 10). However, a peak broadening observed is attributed to the impact of humic acid on the particle size and solid phase texture. Changes in particle size may affect the solubility behavior of the solid phase, since the total energy of smaller particles is different and one has to distinguish between so called macro- and microsolubility [20].

On the other hand the solubility measurements show a slight but significant difference between the $\log \mathrm{K}_{\mathrm{sp}}$ evaluated for the $\mathrm{U}(\mathrm{VI})$ solid phases in solutions

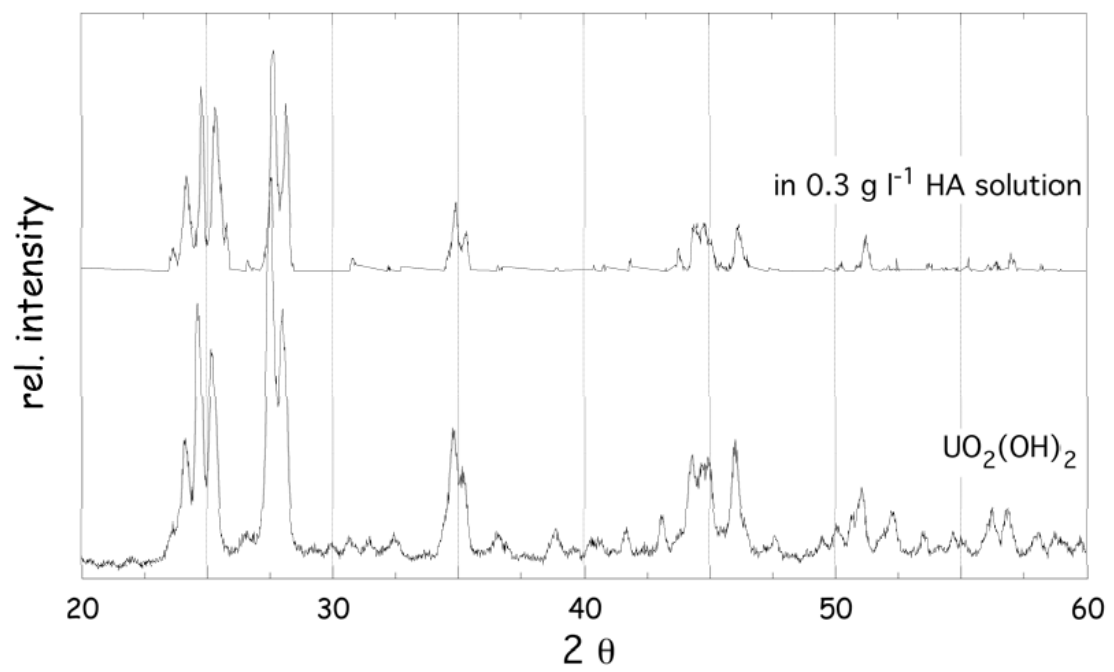

Figure 10: XRD diffractograms of of $\mathrm{UO}_{2}(\mathrm{OH})_{2}$ formed in $\mathrm{HA}$-free solution and in the presence of $\mathrm{HA}\left([\mathrm{HA}]=0.3 \mathrm{gl}^{-1}\right)$. 
without humic acid and solutions containing humic acid. The extent of the effect depends on the stability of the corresponding solid phase. For the $\mathrm{UO}_{2}(\mathrm{OH})_{2}$ solid phase the effect is observable only at increased humic acid concentration ( $[\mathrm{HA}] \geq 0.3 \mathrm{~g} \mathrm{I}^{-1}$ ), whereas the stability of the $\mathrm{UO}_{2} \mathrm{CO}_{3}$ solid phase is affected even at lower humic acid concentration $\left(\left([\mathrm{HA}]=0.3 \mathrm{~g} \mathrm{l}^{-1}\right)\right.$. Generally, the solubility of the $\mathrm{U}(\mathrm{VI})$ solid phases prepared in the presence of humic acid increases with increasing humic acid concentration (Figure 11). This effect is mainly attributed also to the humic acid complexation of $\mathrm{U}(\mathrm{VI})$. However, because at the $\mathrm{pH}$ range, at which the measurements were carried out, the impact of hydrolysis and humic acid complexation on the solubility is negligible, this effect is solely ascribed to microsolubility effects $[8,9]$.

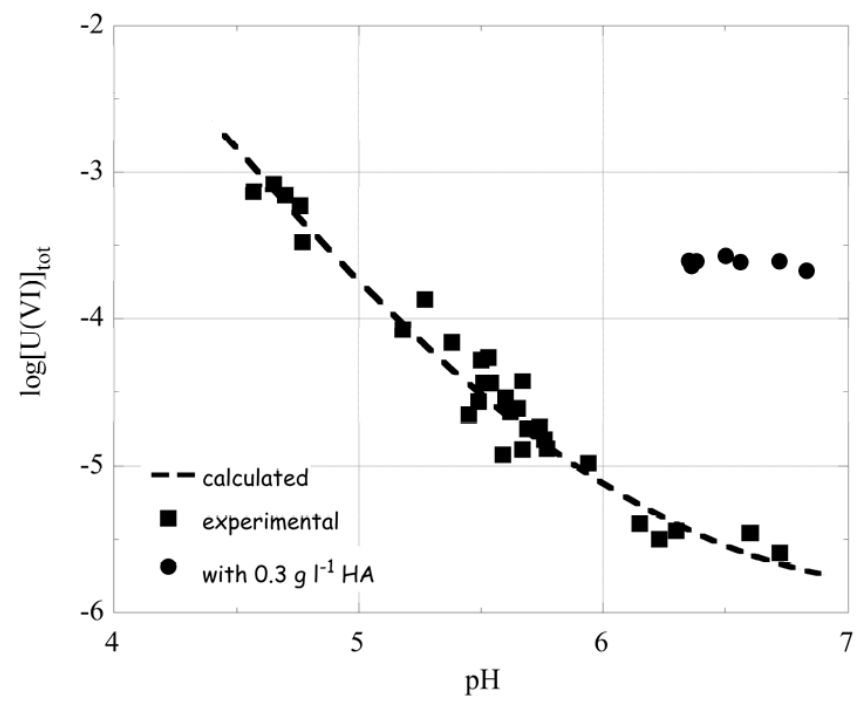

Figure 11: Solubility curves of the $\mathrm{UO}_{2}(\mathrm{OH})_{2}$ solid phases prepared in presence and absence of $\mathrm{HA}\left([\mathrm{HA}]=0.3 \mathrm{~g} \mathrm{I}^{-1}\right)$ under normal atmospheric conditions.

Generally, the effect of humic acid on the solubility of solid phases (when complexation reaction aren't involved) is attributed to microsolubility effects related to the size of the solid phase particles. The effect of humid acid on the texture and particle size of solid phases formed can be attributed to the polyelectrolytic character and the gelatinous-type matrix existing in aqueous humid acid suspensions. In those suspensions the negatively charged moieties (e.g. deprotonated carboxylic acids) of the humic acid form hydrophilic cavities of negatively charged internal surface, which attracts positively charged species such metal cations. Obviously, the formation of the solid phases upon alkaline precipitation in humic acid containing solutions occurs within those cavities, which depending on their size affect to a certain extent the particle size and texture. The extent of this effect depends on the humic acid concentration in the system but the stability of the solid phase, which is thermodynamically described by the solubility product $\left(\mathrm{K}_{\mathrm{sp}}\right)$ is a key parameter determining the extent of matrix effects. Figure 12 summarizes graphically this effect, indicating that the less affected solids are $\mathrm{M}(\mathrm{OH})_{4}$ and $\mathrm{LnPO}_{4}$ and the most affected the $\mathrm{M}(\mathrm{VI})$ and $\mathrm{M}(\mathrm{III})$ carbonate solid phases. According to the data shown in Figure $\mathbf{1 2}$ the relative change in particle size is equal to the square of the $\log \mathrm{K}_{\mathrm{sp}}$.

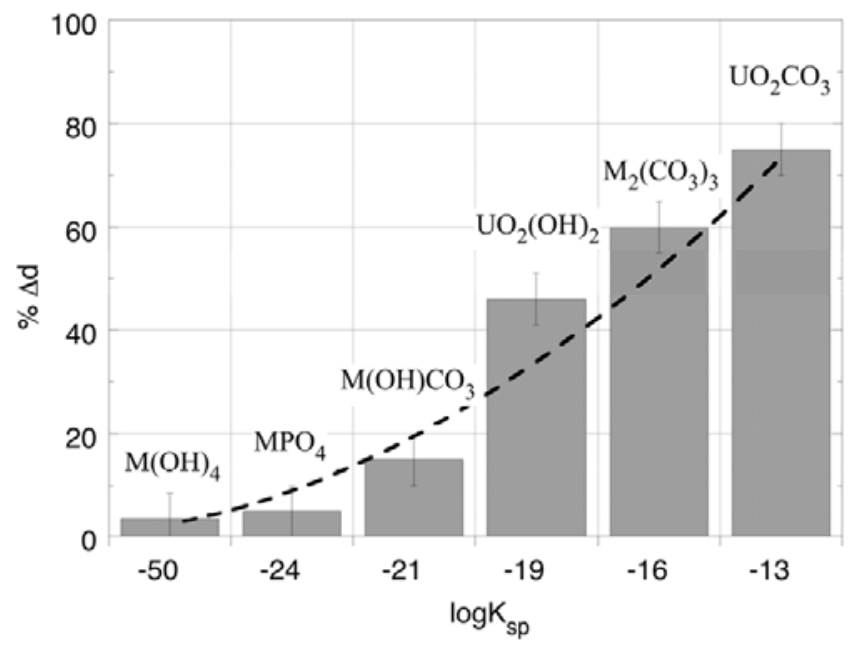

Figure 12: Relative change in the particle size as a function of the solubility product $\left(\log \mathrm{K}_{\mathrm{sp}}\right)$ of solid phases of polyvalent metal ions precipitated in the presence of humic acid.

Nevertheless, the changes in the solid phase solubility because of microsolubility effects are relatively small and within the uncertainties of the solubility product values given in literature for the corresponding solid phases. Hence, the impact of humic acids on the chemical behavior and migration of polyvalent metal ions (e.g. actinides) in the geosphere, because of their impact in the formation of secondary solid phases, is expected to be of minor relevance and significantly lower than their impact because of the formation of humic complexes. However, coating of nano-sized solid phase particles with humic acid colloids could increase their stability in the aqueous phase and result in enhanced contaminant mobility. Since colloidal transport plays an important role in contaminant/ radionuclide transport, the formation of HA-coated inorganic particles could be a subject to further investigation.

\section{CONCLUSIONS}

Based on the results obtained from this study it can be concluded that: 
The formation of secondary solid phases of polyvalent metal ions is not significantly affected by the presence of humic acids in an aqueous system. However, if redox-sensitive (oxidizing) species are present, these may be reduced by humic acid leading to the formation of solid phases corresponding to lower oxidation states of the redox-sensitive metal species.

Spectroscopic data indicate the formation of only pure solid phases and the humic acid is just coprecipitated, most probably adsorbed onto the solid particles.

The adsorption of humic acids on the particle surface affects texture, particle size and water holding capacity of the solid phase formed. The extent of this effect depends strongly on the solid phase stability and the highest for the $\mathrm{M}(\mathrm{VI})$ and $\mathrm{M}(\mathrm{III})$ carbonate and lowest for the $\mathrm{LnPO}_{4}$ and $\mathrm{M}(\mathrm{OH})_{4}$ solid phases.

Generally, the impact of humic acids on the chemical behavior and migration of polyvalent metal ions (e.g. actinides) in the geosphere, because of their impact in the formation of secondary solid phases, is expected to be of minor relevance.

\section{ACKNOWLEDGEMENT}

The research leading to these results has received funding from the Cyprus Research Promotion Foundation (Grant agreement No. MENEK/ENI $\Sigma X /$ 0308/05 and ПРО $\Sigma$ ВА $\Sigma$ H/EPYE $\Xi / 0308 / 02$ ) and partially by the University of Cyprus.

\section{REFERENCES}

[1] Kim JI. The Chemical Behavior of Transuranium Elements and Barrier Functions in Natural Aquifer Systems. Mater Res Soc Symp Proc 1993; 294: 3-21. http://dx.doi.org/10.1557/PROC-294-3

[2] Seaborg GT. Overview of the actinide and lanthanide (the f) elements. Radiochim Acta 1993; 61: 115-22.

[3] Choppin GR. Comparative solution chemistry of the $4 \mathrm{f}$ and $5 f$ elements. J Alloys Comp 1995; 223: 174-9. http://dx.doi.org/10.1016/0925-8388(94)09002-5

[4] Pashalidis I, Runde W, Kim Jl. A study of solid-liquid phase equilibria of $\mathrm{Pu}(\mathrm{VI})$ and $\mathrm{U}(\mathrm{VI})$ in aqueous carbonate systems. Radiochim Acta 1993; 61: 141-6.

[5] Meinrath G, Kato Y, Kimura T, Yoshida Z. Solid-Aqueous Phase Equilibria of Uranium under Ambient Conditions. Radiochim Acta 1996; 75: 159-67.

[6] Meinrath G, Takeishi $\mathrm{H}$. Solid-liquid equlibria of $\mathrm{Nd}^{3+}$ in carbonate solutions. J Alloys Comp 1993; 194: 93-9. http://dx.doi.org/10.1016/0925-8388(93)90651-3
[7] Runde W, Meinrath G, Kim Jl. A study of solid-liquid phase equilibria of trivalent lanthanide and actinide ions in carbonate systems. Radiochim Acta 1992; 58: 93-100.

[8] Kolokassidou C, Pashalidis I. Effect of humic acid on the solid phase stability and solubility of $\mathrm{UO}_{2}(\mathrm{OH})_{2}$. J Radioanal Nucl Chem 2009; 279: 523-8.

http://dx.doi.org/10.1007/s10967-007-7316-2

[9] Antoniou S, Kolokassidou C, Polychronopoulou K, Pashalidis I. Effect of humic acid on the solid phase stability of $\mathrm{UO}_{2} \mathrm{CO}_{3}$. J Radioanal Nucl Chem 2009; 279: 863-6. http://dx.doi.org/10.1007/s10967-008-7367-4

[10] Antoniou S, Pashalidis I. The Effect of Natural Organic Matter on the Formation and Solubility of $\mathrm{M}(\mathrm{OH})_{4}$ Solid Phases $\left(\mathrm{Th}(\mathrm{OH})_{4}, \quad \mathrm{Zr}(\mathrm{OH})_{4} \quad \mathrm{Ce}(\mathrm{OH})_{4}\right)$. In: Lekkas DF, editor. Proceedings to the 11th International Conference on Environmental Science and Technology. Chania - Crete, Greece 3-5 September 2009. University of the Aegean 2009: pp. 1-8.

[11] Antoniou S, Pashalidis I. The Effect of Natural Organic Matter on the Solid Phase Stability and Solubility of $\mathrm{Th}(\mathrm{OH})_{4}$. In: González-Vila JM, editor. Proceedings to the 15th IHSS Meeting. Tenerife - Canary Islands 2010. Institute for Natural Resources and Agrobiology 2010; pp.157-60.

[12] Antoniou S, Pashalidis I, Gessner A, Kumke MU. The effect of humic acid on the formation and solubility of secondary solid phases $\left(\mathrm{Nd}(\mathrm{OH}) \mathrm{CO}_{3}\right.$ and $\left.\mathrm{Sm}(\mathrm{OH}) \mathrm{CO}_{3}\right)$. Radiochim Acta 2011; 99: 217-23.

http://dx.doi.org/10.1524/ract.2011.1812

[13] Antoniou S, Pashalidis I, Gessner A, Kumke, MU. Spectroscopic investigations on the effect of humic acid on the formation and solubility of secondary solid phases of $\left(\mathrm{Ln}_{2}\left(\mathrm{CO}_{3}\right)_{3}\right.$. J Rare Earth 2011; 29: 516-21. http://dx.doi.org/10.1016/S1002-0721(10)60490-5

[14] Kitano Y, Kanamori N, Tokuyama A. Effects of organic matter on solubilities and crystal forms of carbonates. Am Zool 1969; 9: 681-8.

[15] Kodona EK, Alexopoulos C, Panou E, Pomonis PJ. SelfOrganized Meso- and Hybridic Phases of Poly(aspartic acid) and Poly(glutamic amino acid) with Cationic Surfactants $\left(C_{n} T A B, n=14,16\right)$ and a Silica Source (TEOS). Chem Mater 2007; 19: 1853-61. http://dx.doi.org/10.1021/cm062878g

[16] Kolokassidou K, Szymczak W, Wolf M, Obermeier C, Buckau G, Pashalidis I. Hydrophilic olive cake extracts: Characterization by physicochemical properties and $\mathrm{Cu}(\mathrm{II})$ complexation. J Haz Mat 2009; 164: 442-7. http://dx.doi.org/10.1016/j.jhazmat.2008.08.016

[17] Lu YW, Laurent G, Pereira H. A novel methodology for evaluation of formation constants of complexes: example of lanthanide-Arsenazo III complexes. Talanta 2004; 62: 95970.

\section{http://dx.doi.org/10.1016/j.talanta.2003.10.030}

[18] Konstantinou M, Kolokassidou K, Pashalidis I. Studies on the interaction of olive cake and its hydrophylic extracts with polyvalent metal ions (Cu(II), Eu(III)) in aqueous solutions. $J$ Haz Mat 2009; 166: 1169-73.

http://dx.doi.org/10.1016/j.jhazmat.2008.12.016

[19] Sparks DL. Environmental Soil Chemistry, $2^{\text {nd }}$ ed. Academic Press; London 2003.

[20] Kellner R, Mermet JM, Otto M, Widmer HM. Analytical Chemistry. Wiley-VCH; Weinheim 1998.

[21] Jenkins R, Snyder RL. Introduction to X-ray Powder Diffractometry. John Wiley \& Sons Inc; New York 1996. 